\title{
PLAZMA GAZLAŞTIRMA TEKNOLOJİSİ İLE KATI ATIK BERTARAFI
}

\author{
Hüseyin TOPAL \\ Gazi Üniversitesi Mühendislik Fakültesi, Makina Mühendisliği Bölümü, Ankara, \\ htopal@gazi.edu.tr
}

(Geliş/Received: 15.03.2014; Kabul/Accepted: 01.09.2015)

ÖZET

Evsel katı atıklardaki artış Türkiye'nin en önemli çevre sorunlarının başında gelmektedir. Bu çevre sorununun çözümü için çevre dostu ve sürdürülebilir çözümler arasında plazma teknolojileri ile katı atık bertarafi en uygun yöntemler arasındadır. Evsel katı atıkların alışılagelmiş termal metotlar ile bertaraf teknolojilerine göre, içeriğinde bulunan çeşitli kimyasal maddeler nedeni ile plazma gazlaştırma teknolojisi yüksek verimli ve güvenilir bir çözümdür. Plazma gazlaştırma, diğer geleneksel yakma teknolojileri gibi bir alevli yakma sistemi değildir. Bu yöntem, organik bileşenleri yanıcı bir gaz olan sentez gazına dönüştürür. Bu çalışmada evsel katı atıkların güvenilir biçimde bertarafi ve birlikte enerji üretmek için kömür ve atıkların ve plazma teknolojisi uygulanması konusunda analitik bir çalışmadır. Bu amaçla, iki metot uygulanmıştır. Birinci metod ile gazlaştırma prosesinde, kütlesel içerikleri bilinen atıkların sentez gazına dönüşümleri ve oluşan sentetik gaz bir matematiksel modelleme ile belirlenmiştir. İkinci metot ile de, aynı prosesi bir bilgisayar simülasyon yazılımı (VMGSim) ile simüle edilmiştir. İki yöntem ile elde edilen sonuçlar karşılaştırılmıştır ve matematiksel modelleme ile simülasyon programından elde edilen sonuçların tutarlı olduğu görülmüştür.

Anahtar Kelimeler: Plazma gazlaştırma, evsel katı atıklar, enerji, bertaraf

\section{PLASMA GASIFICATION TECHNOLOGY FOR SOLID WASTE DISPOSAL}

\begin{abstract}
Increasing amount of municipal waste is one of the major environmental problems in Turkey. Among several ecofriendly and sustainable methods of waste disposal, plasma technology can be counted as one the most appropriate methods. Considering different chemicals that waste contains, gasification with plasma technology is a much more efficient and safe compared to the conventional thermal disposal methods. Plasma gasification technology is much different than thermal burning. When gasified by plasma, organic compounds of the municipal waste is transformed into syngas. In this research, safe disposal of municipal solid waste and energy production by application of plasma gasification technology to waste and coal mixtures is studied. In this regard two different methods have been used. For the first case transformation of waste with known ingredient mass fractions to syngas and produced syngas is analyzed with a mathematical model. For the second case the same process is studied using a computer simulation software (VMGsim). Results obtained from these two methods are compared and consistency of these two set of results were observed.
\end{abstract}

Keywords : Plasma gasification, municipal solid waste, energy, disposal

\section{GİRISŞ (INTRODUCTION)}

Atık en basit tanımı ile "ihtiyaçlarımızı karşılamak üzere kullandığımız maddelerin, 0 an için kullanılmayan veya kullanıldıktan sonra atılan kısmıdır." Sanayide, ulaşımda, tarımda, turizmde, inşaat sektöründe, üretim yaparken, hizmet verirken, çok sayıda madde ve malzeme biçim değiştirir. Bu faaliyetler için enerji sağlarken ve enerji kullanırken, gaz, sıvı ve katı halde atıklar ve artıklar ortaya çıkar. $\mathrm{Bu}$ atıkların bir bölümü nihai olarak bertaraf edilirken, bir bölümü geri kazanılarak, yeniden kullanılabilir [1].

Atıklardan enerji üretimi günümüzde özellikle gelişmiş ülkeler başta olmak üzere tüm Dünya'da ilgi 
gören bir konudur. Atıklar bünyelerinde bulundurdukları kalorifik değerlere ve kirletici potansiyellerine göre farklı enerji dönüşüm yöntemleri kullanılarak imha edilirler. $\mathrm{Bu}$ durumda tarımsal ve orman atıkları çevresel kirleticiler bakımından en masum katı ve sıvı atıklar ise en riskli atık grubunda yer almaktadır.

Ülkemizde biyokütle türünde sayllabilecek enerji bitkileri, tarımsal ve orman atıklarının yakılması üzerine çok sayıda çalışma yapılmıştır [2, 3, 4]. Son yıllarda yakma teknolojileri, bazı katı atıkların enerji üretilmesi ve imha edilmesinde kullanılmaktadır. $\mathrm{Bu}$ tesislerden biri İzmit Büyükşehir Belediyesi yatırımı olan "Tehlikeli Atıklar Yakma Tesisi" dir. Bu tesiste yüksek yatırım maliyetli ve işletimi oldukça pahalı yakma ve baca gazı aritma sistemleri kullanılmaktadır. Tesisin temel görevi tehlikeli atık bertarafidır. Plazma teknolojileri, tehlikeli sınıfina giren atıkların bertarafında pahalı çevre yatırımlarını gerekli olmaktan çıkartarak daha kolay işletim ve daha düşük işletme maliyetleri ile çevre açısından çok daha düşük riskler ile atıkların bertarafinda kullanılabilmektedir.

Plazma teknolojisi, elektriksel bozunma olarak kabul edilen bir işlem olan, bir proseste elektrik akımını bir gaz içerisinden geçirerek aralıksız bir elektrik arkı oluşturmayı kapsar. Sistemdeki elektriksel özdirençten dolayı, gaz moleküllerinden elektronları ayıran, iyonlaşmış bir gaz akışı veya plazma fazı oluşur ve oldukça yüksek sicaklık seviyesinde 1s1 açığa çıkar. $2000{ }^{\circ} \mathrm{C}^{\prime}$ de, gaz molekülleri atomlarına ayrılır ve sıcaklık $3000{ }^{\circ} \mathrm{C}$ 'ye yükseldiğinde gaz molekülleri elektron kaybeder ve iyonlaşırlar. $\mathrm{Bu}$ durumda oluşan gaz, sıvılardaki gibi bir viskoziteye sahiptir ve serbest elektrik yükleri gaza göre yüksek, metallerinkine yakın bir elektriksel iletkenlik verir [5].

Diğer bertaraf ve yakma yöntemlerine nazaran plazma teknolojisi, açığa çıkardığı ürünleri sayesinde çevreci bir teknolojidir. Gazlaştırma sırasında ağır metaller reaktörün en alt bölümünde ergiyerek seramik yapısında çamur haline gelmekte ve dişarıya herhangi bir ağır metal çıkışı olmamaktadır. Yüksek sıcaklıklara çıkıldığından dolayı, atık yakma teknolojilerinin en önemli sorunu olan dioksin ve furan grupları bu teknoloji ile çalışılan yüksek sicaklıklar nedeni ile oluşmamaktadır. Bu avantajından dolayı plazma teknolojisi çevresel riskleri çok daha az olduğundan çevre dostu olarak gelişmiş ülkeler tarafindan tercih edilmektedir [6]. Son y1llarda plazma yakma teknolojileri ile katı atıklardan enerji üretimi konusunda yapılan teorik ve uygulamalı pek çok çalışma bulunmaktadır. $\mathrm{Bu}$ çalışmalar arasında özellikle enerji üretiminde plazma teknolojisinin kullanımı sonucu üretilen elektrik enerjisinin maliyetinin yüksek olduğunu göstermektedir [7]. Ancak plazma yardımcılığında kömür yakılması vb uygulamaların özellikle kömür yakma teknolojilerine alev stabilizasyonunun garanti altında tutulması bakımından avantajlar sağlamaktadır. Bu sayede ek yakıt kullanımının önüne geçilmekte ve gerekli olan enerjinin hızlı ve yüksek seviyede sağlanması sayesinde kömür kullanan termik santrallerde enerji üretim maliyetlerinin düşürülmesi mümkün olabilmektedir [8-9]. Uluslararası pek çok çalışmada en önemli unsurun katı atıkların içerdiği tehlikeli atıkların tanımlanması olduğu rapor edilmektedir. Tehlikeli atık içeriği bulunan evsel atıklar için atığın miktarına ve türüne göre bertaraf ve filtreleme sistemleri büyük önem kazanmaktadır [10]. Ambarish ve arkadaşları Amerikan hava kuvvetlerine ait Basic Expeditionary Airfield Resources (BEAR) ve halı atıkları adını verdikleri katı atıkları kurmuş oldukları plazma gazlaştırma-katılaştırma prosesinde bertaraf etmişler ve açığa çıkan gaz yüzdelerini deneysel olarak belirlemişlerdir. Bu çalışma katı miktarı fazla olan bu türde atıklardan belli oranda $\mathrm{CO}$ oluştuğunu ancak büyük oranlarda ise karbonizasyon sonucu katı ve inert atıkların oluştuğu anlaşılmaktadır [11]. Tzeng ve arkadaşları Institute of Nucleer Energy Research Merkezinde (INER) yaptıkları çalışmada radyoaktif atıkların bertarafinda kullanılmak üzere $100 \mathrm{~kW}$ gücünde bir transfersiz plazma torcu ve 10 $\mathrm{kg} /$ saat besleme kapasiteli bir bertaraf firını tasarımı yapmışlardır. İşletme sıcaklığını $1700-1650{ }^{\circ} \mathrm{C}$ 'de sabit tutup ortalama plazma gazı sıcaklığını 5000$6000{ }^{\circ} \mathrm{C}$ olarak hesaplamışlardır. Plazma reaktöründe kullanılan katodun çalışma ömrünü 150 saat, anodun ömrünü ise 500 saat olarak tespit etmişlerdir. Bu çalışmadaki maksimum çalışma voltajı $600 \mathrm{~V}$, max çalışma akımı $200 \mathrm{~A}$, hava besleme hızı 100-700 santilitre/dakika, 1sınan gazın entalpisi 6-10 MJ/kg olarak hesaplanmıştır. Sistemin maksimum enerji çevrimi verimi \% 87 olarak belirlenmiştir [12]. Moustakas ve arkadaşları 2005 yılında yaptıkları çalışmada plazma gazlaştırma katılaştırma işlemi için laboratuvar ölçekli bir kazan tasarımı ve bu kazana bağlı bir arıtma sistemi tasarımı yapmış ve bu sistemde belirledikleri atıkları gazlaştırmışlardır. Yaptıkları çalışmalarda eğer atığın içerisinde katılaştırmayı sağlayacak kadar silika yok ise dışarıdan silika ilavesi yapılmıştır. Yaptıkları çalışmalar sonucunda gazlaştırmadan açığa çıkan sentez gazının kompozisyonunda hacimsel ortalama olarak sirasıyla $\mathrm{H}_{2}, \mathrm{CO},\left(\mathrm{CO}_{2}+\mathrm{N}_{2}\right)$ gazları, $24-43 \%$, 25-44\%, 10-26\% olarak ölçülmüştür [13]. Galeno ve arkadaşları Cassino Üniversitesinde yaptıkları çalışmada plazma gazlaştırma ünitesi ile yakıt hücresini entegre etmeyi başarmışlardır. Plazma gazlaştırma ünitesinde saatte $3600 \mathrm{~kg} \quad \mathrm{l} \mathrm{k}$ atık beslemesi yapılırken sentetik gaz içerisinde \% 28,65 $\mathrm{H}_{2}$ ve \% 37,37 CO konsantrasyonları elde edilmiştir. Plazma gazlaştırma ünitesinden açığa çıkan sentetik gazı 1S1 değiştiricisinde istenilen sıcaklığa indirildikten sonra $100 \mathrm{~kW}$ 'lık yakıt hücresine gönderilerek enerji üretimi sağlanmıştır [14]. Huamg ve arkadaşları plazma gazlaştırma prosesini piroliz prosesine uyarlamış olup polietilen, polipropilen, lastik kauçuk, ilaç atığı tarım artıkları ve kömür üzerinde piroliz gazlaştırması yapmışlardır. Yapılan 
Tablo 1. Plazmanın teknolojisinin yakma yöntemine göre üstünlükleri (The advantages of plasma technologies in comparison to combustion methods) [20]

\begin{tabular}{|l|l|}
\hline Plazma Gazlaştırma & Yakma \\
\hline Sentetik gaz üretimi sırasında zararlı emisyonlar oluşmaz. & $\begin{array}{l}\text { Gaz emisyonları; yüksek düzeyde sera gazı, diğer hava } \\
\text { kirletici maddeler, dioksin ve furan grupların içerir. }\end{array}$ \\
\hline Hidrokarbon ve duman emisyonu oluşmaz. & $\begin{array}{l}\text { Yüksek oranlarda hidrokarbon ve duman emisyonu açığa } \\
\text { çıkabilir. }\end{array}$ \\
\hline $\begin{array}{l}\text { Ticari değeri olan cürufları tesirsiz kılmak için katılar 1/150 } \\
\text { oranında az hacim kaplar. }\end{array}$ & $\begin{array}{l}\text { Katıların \%30’u katı bir atık oluşturur. Bu atıklar } \\
\text { potansiyel zararlı katı atık olan kül olarak kalır. }\end{array}$ \\
\hline Oksijeni alınmış bir değiştirici kanalda işlem gerçekleşir. & Fazla hava, yakma firınına eklenir. \\
\hline $\begin{array}{l}\text { Plazma jeneratörü termal işlem için gerekli tüm enerjiyi } \\
\text { sağlamaktadır. }\end{array}$ & İşlemi sürdürmek için ek yakıt gerekir. \\
\hline Atıklar zengin enerjili gaz yakıt olarak ayrı̧şırılır. & Tüm enerji 1sıya dönüştürülür. \\
\hline
\end{tabular}

deneyler sonucunda adı geçen atıkların deneysel olarak piroliz işleminden sonra elde ettikleri sentez gazlarının içerikleri rapor edilmiştir [15]. Kataou ve arkadaşlarının belediye katı atıklarının plazma ile gazlaştırılarak bertarafi üzerine yapmış oldukları çalışmada gazlaştırma-katılaştırma prosesi sonucunda kazanın dibinde, vitrifiye çamurundaki ve metal kısımda kalan ağır metallerin ortalama oranları belirlenmiştir. $\mathrm{Bu}$ deneylerde özellikle klorun toz biçiminde ortamdan uzaklaştığını göstermektedir. $\mathrm{Bu}$ deneysel sistemin toplam 1sı miktarı dolaylı yöntem ile $723 \mathrm{~kW}$ olarak belirlenmiştir [16]. Mountouris ve arkadaşları Atina National Technical Üniversitesi'nde yapmış oldukları çalışmada arıtma çamurlarının içerisinde bulunan nemin, plazma gazlaştırma işleminden açığa çıkan sentetik gazın termal kalitesi üzerindeki etkilerini incelemişlerdir. Arıtma çamuru içerisinde bulunan nemin oranı arttıkça gazlaştırma işlemi için gerekli olan elektrik enerjisi miktarı artmış ve bununla birlikte sentez gazının kalorifik değeri azalmıştır [17].

\section{KATI ATIKLARIN BERTARAFI VE ENERJI ÜRETIMİ (SOLID WASTE DISPOSAL AND ENERGY PRODUCTION)}

Katı atıklar kaynakları ister belediye atıkları olsun isterse endüstriyel atıklar içeriklerindeki ekolojik çevreye zararlı olan maddeler tam olarak bilinemez. Tehlikeli atıkların düzenli bir kaynaktan geliyor olması kontrol bakımından oldukça avantaj sağlamaktadır. Ancak özellikle klorlu ve florlu bileşiklerin oluşturduğu dioksin ve furan son derece yüksek kanserojen etkilere sahip emisyonların önlenmesi sistem tasarımında ve işletilmesi aşamalarında büyük dikkat gerektirmektedirler. Enerji potansiyeli yüksek olan tarımsal atıklar ve orman atıkları gibi atıklardan enerji üretilerek berataraf yöntemleri yaygın olarak kullanılmakta ve büyük bir emisyon problemi oluşturmamaktadırlar. Ancak evsel katı atıklar ve arıtma çamurları gibi katı ve sıvı karışık atıkların bertaraf konusu bu türde emisyonlar bakımından direkt yakma metodu kullanılarak yapılmamalıdır. Bu aşamada tüm Dünya'da gerek gazlaştırma gerekse yakma uygulamaları ile avantajları olan plazma teknolojileri ile atık bertarafi önem kazanmaktadır. Plazma teknolojisinin yakma yöntemine göre üstünlükleri Tablo 1 de verilmiştir.

\subsection{Yakma Teknolojilerine Bakış (Overview to Combustion Technologies)}

Atık bertarafinda kullanılan yakma yöntemlerini şu şekilde sıralayabiliriz [18];

1. Izgaralı yakma sistemleri,

2. Akışkan yataklı firınlar,

3. Döner firınlar,

4. Alternatif sistemler,

- Yaş oksidasyon,

- Piroliz,

- Gazlaştırma ve kombine sistemler,

5. Plazma Teknolojileri

$\mathrm{Bu}$ teknolojiler kurulum maliyetleri nedeni ile farklı ekonomik seviyelerdeki ülkelerde farklı tercihler yapılmak üzere kullanılmaktadır. Klasik yöntemler ile yakma işlemlerinde emisyon kontrolü genelde daha zordur ve kontrol için yüksek işletme masrafları gerekmektedir. Alternatif sistemlerde ise genelde gazlaştırma ve piroliz sonucu oluşan ara ürünler çevre bakımından büyük sorunlar içermemektedir. Ancak atıklar içerisinde ağır metal bulunması durumunda halen risk taşımaktadır.

Plazma teknolojileri ise işletme sıcaklıklarının oldukça yüksek olması nedeni ile reaksiyon sonucunda gazlaşma ürünleri ve katı seramik-cam yapısında kül oluşmaktadır. Her iki ürün de zararlı bileşenler bakımından en az riske sahiptir.

\subsection{Atıkların Termal Plazma ile Bertarafi (Thermal Plasma Treatment of Wastes)}

Plazma reaktörleri kullanarak eritmede veya cam oluşturucuların eklenmesiyle atığın içerdiği katı maddeyi camsı yapı içinde tutulabilir. Camlaştırılmış ürün tekrar kullanım imkanının yanında güvenle tekrar geri kazanılabilir hurda metaller gibi yüksek değerli diğer ürünleri de elde etme imkanı sunar. Bunlara ek olarak, plazmalar tehlikeli organik 
bileşimleri termal yolla sade ve zararsız gazlara ayrıştırabilir. Alternatif olarak, gazlaştırma veya piroliz kullanılarak organik atıklar fosil yakıt yerine kullanılabilecek sentez gazına dönüştürülebilir [18]. Plazma ile tehlikeli atıkların bertarafi işleminin en büyük dezavantajı pahalı bir enerji kaynağı olan elektriği kullanmasıdır. Bununla birlikte sürdürülebilir bir atık yönetimi sağlamak için uzun dönemli bir yatırım olarak düşünüldüğünde ekonomik açıdan uygun olduğu anlaşılacaktır. Ayrıca ortaya çıkacak olan sentetik gazın içeriği ve kalorifik değeri dikkate alındığında elektrik enerjisi tüketimi kabul edilebilir seviyede kalmaktadır [19].

\subsection{Plazma Teknolojisinin Diğer Bertaraf} Yöntemlerine Göre Üstünlükleri (The Advantages of Plasma Compared to the Other Disposal Methods)

Plazma teknolojileri ile evsel katı atıkların bertarafinın geleneksel Yakma teknolojilerine göre üstünlükleri Tablo 1'de verilmiştir. Yukarıdaki tabloda maddeler halinde verilen ve çarpıcı üstünlükleri bulunan plazma teknolojisi özellikle tehlikeli atıkların bertarafı konusunda kabul gören bir teknolojidir.

\subsection{Metot (Methods)}

$\mathrm{Bu}$ çalışmada kullanılan plazma teknolojisine ve hesaplama metoduna ait veriler aşağıda açıklanmıştır.

\section{Plazma ünitesi (Plasma Unit)}

Bir plazma katı atık bertaraf tesisinde tesise gelen atığın bertaraf için izlediği yol ve süreç Şekil 1'de gösterilmiştir. Beslenen atık kurutucuda fazla nemi alındıktan sonra plazma torçu yardımıyla gazlaştırma reaktöründe sentez gazına dönüştürülür (Şekil 2). Sentez gazı da içerisinde bulunan toz, ağır metal gibi partiküllerinden arındırılmak üzere toz tutuculara ve absorber/scrubber gibi temizleme birimlerine gönderilerek temizlenir ve 1 s1 enerjisine dönüştürülmek üzere ikincil yanma kazanına gönderilir. Burada yakılan sentez gazından arta kalan yanma gazları da temizlenerek bacaya verilir.

\section{Kinetik parametreler (Kinetic Parameters)}

Gazlaştırma işlemi gazlaştırma kazanı içerisinde oluşan karbon bazlı reaksiyonlar kinetik parametreler tarafindan kontrol edilmektedir. Bu parametreler ve A, E, r, Alpha $(\alpha)$ ve Beta $(\beta)$ parametreleri olup aşağıda verilen reaksiyonlar ile gösterildiği gibi ilişkilendirilebilir [21]. Bu reaksiyonların kimyasal dengede oldukları varsayılmış ve gazlaşma reaksiyonlarında kullanılan denge sabitlerinin sicaklık ile değişimleri grafik biçiminde Şekil 3'de verilmiştir. Aşağıda verilen 1-14 numaralı denklemler Paket program tarafindan kullanılmaktadır.

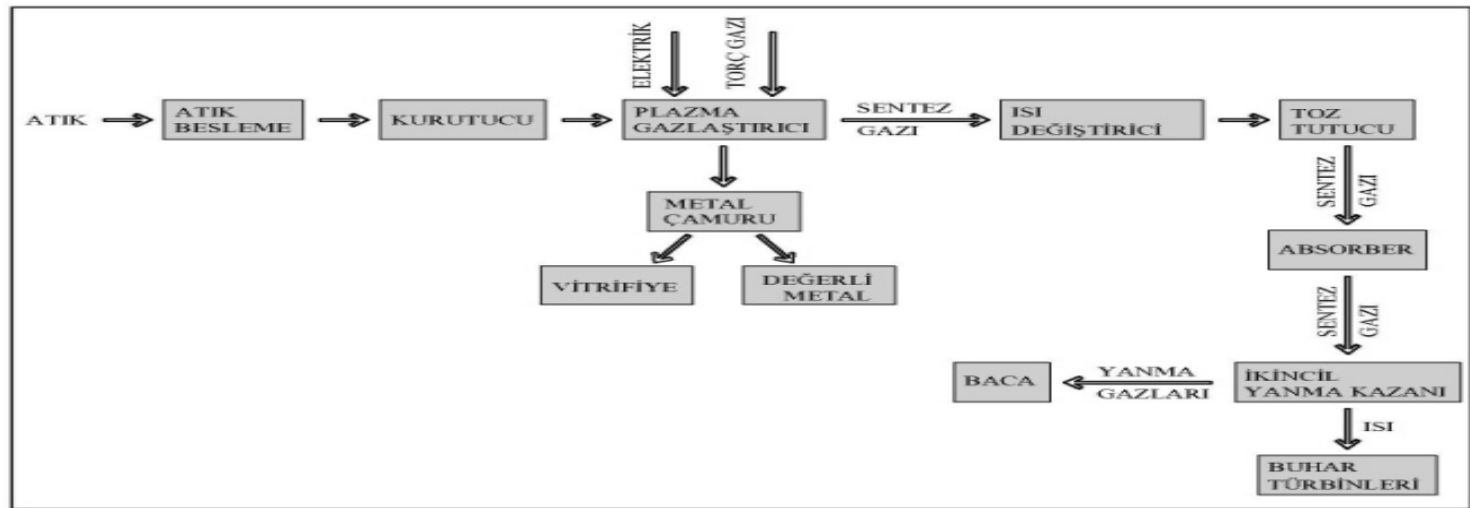

Şekil 1. Plazma gazlaştırma tesis akım şeması (Plasma gasification plant flow chart)

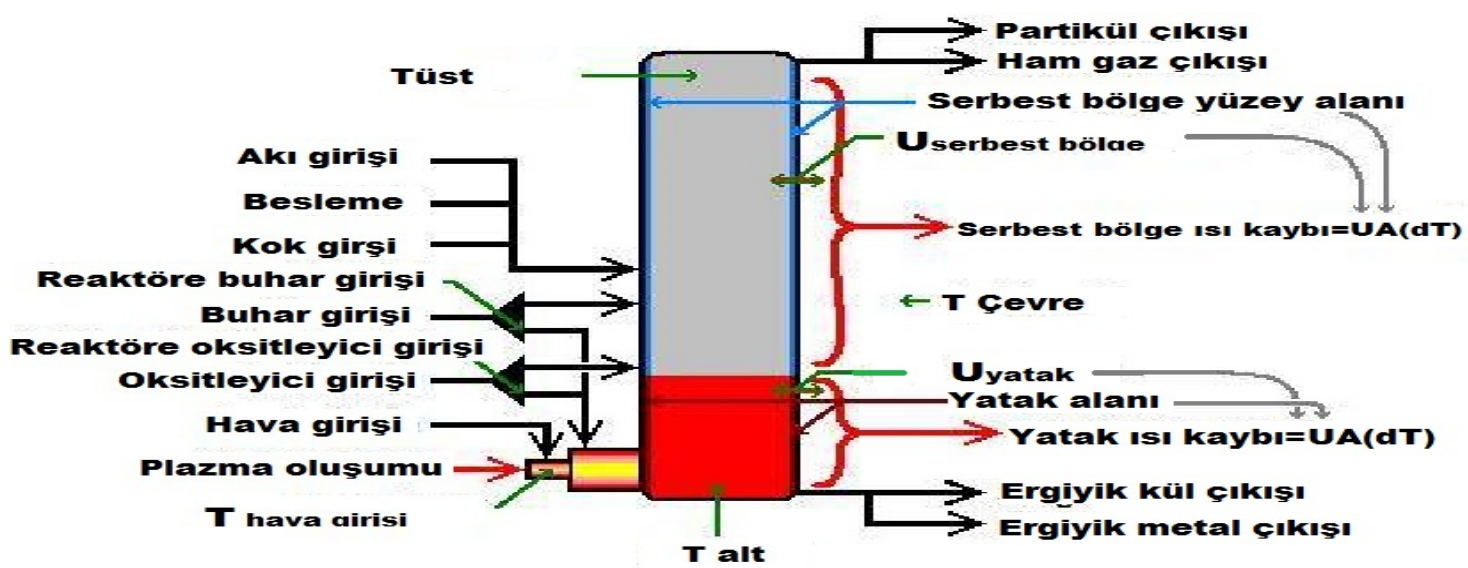

Şekil 2. Plazma gazlaştırma ünitesi şematik görünümü (Plasma gasification unit schematic view) 


$$
\begin{aligned}
& 2 \mathrm{C}+\mathrm{O}_{2} \longleftrightarrow 2 \mathrm{CO} \\
& \mathrm{C}+\mathrm{CO}_{2} \longleftrightarrow 2 \mathrm{CO} \\
& \mathrm{C}+\mathrm{H}_{2} \mathrm{O} \longleftrightarrow \mathrm{CO}+\mathrm{H}_{2} \\
& \mathrm{C}+\mathrm{O}_{2} \longleftrightarrow \mathrm{CO}_{2} \\
& \mathrm{CO}+\mathrm{H}_{2} \mathrm{O} \longleftrightarrow \mathrm{CO}_{2}+\mathrm{H}_{2} \\
& \mathrm{C}+2 \mathrm{H}_{2} \longleftrightarrow \mathrm{CH}_{4} \\
& \mathrm{CO}+3 \mathrm{H}_{2} \longleftrightarrow \mathrm{CH}_{4}+\mathrm{H}_{2} \mathrm{O}
\end{aligned}
$$

- $\mathrm{C}+\frac{1}{2} \mathrm{O}_{2} \rightarrow \mathrm{CO}$$$
r_{C O_{1}}=A_{C O_{1}} P_{C} P_{O_{2}}{ }^{0.5}\left(1-\frac{1}{K_{C O_{1}}} \frac{P_{C O}}{P_{C} P_{O_{2}} 0.5}\right) \exp \left(\frac{-E_{C O_{1}}}{T}\right) \log _{10} K_{C O_{1}}=\frac{\alpha}{T}+\beta
$$$$
\text { - } \mathrm{C}+\mathrm{CO}_{2} \rightarrow 2 \mathrm{CO}
$$$$
r_{\mathrm{CO}_{2}}=A_{\mathrm{CO}_{2}} P_{C} P_{\mathrm{CO}_{2}}\left(1-\frac{1}{K_{\mathrm{CO}_{2}}} \frac{P_{C O}{ }_{C} P_{C O}}{2}\right) \exp \left(\frac{-E_{C O_{2}}}{T}\right) \log _{10} K_{\mathrm{CO}_{2}}=\frac{\alpha}{T}+\beta
$$$$
\text { - } \mathrm{C}+\mathrm{H}_{2} \mathrm{O} \rightarrow \mathrm{CO}+\mathrm{H}_{2}
$$$$
r_{\mathrm{CO}_{3}}=A_{\mathrm{CO}_{3}} P_{C} P_{\mathrm{H}_{2} \mathrm{O}}\left(1-\frac{1}{K_{\mathrm{CO}_{3}}} \frac{P_{\mathrm{CO} P_{\mathrm{H}_{2}}} P_{\mathrm{P}_{2} \mathrm{O}}}{T}\right) \exp \left(\frac{-E_{\mathrm{CO}_{3}}}{T}\right) \log _{10} K_{\mathrm{CO}_{3}}=\frac{\alpha}{T}+\beta
$$$$
\text { - } \mathrm{C}+\mathrm{O}_{2} \rightarrow \mathrm{CO}_{2}
$$$$
r_{\mathrm{CO}_{2} 1}=A_{\mathrm{CO}_{2} 1} P_{C} P_{O_{2}}\left(1-\frac{1}{K_{\mathrm{CO}_{2} 1}} \frac{P_{\mathrm{CO}_{2}}}{P_{C} P_{\mathrm{O}_{2}}}\right) \exp \left(\frac{-E_{\mathrm{CO}_{2} 1}}{T}\right) \log _{10} K_{\mathrm{CO}_{2} 1}=\frac{\alpha}{T}+\beta
$$$$
\text { - } \mathrm{CO}+\mathrm{H}_{2} \mathrm{O} \leftrightarrow \mathrm{CO}_{2}+\mathrm{H}_{2}
$$$$
r_{\mathrm{CO}_{2} 2}=A_{\mathrm{CO}_{2} 2} P_{\mathrm{CO}} P_{\mathrm{H}_{2} \mathrm{O}}\left(1-\frac{1}{K_{\mathrm{CO}_{2} 2}} \frac{{ }_{\mathrm{CO}_{2} \mathrm{P}_{\mathrm{H}}}}{P_{\mathrm{CO}} P_{\mathrm{H}_{2} \mathrm{O}}}\right) \exp \left(\frac{-E_{\mathrm{CO}_{2} 2}}{T}\right) \log _{10} K_{\mathrm{CO}_{2} 2}=\frac{\alpha}{T}+\beta
$$$$
\text { - } \quad \mathrm{C}+2 \mathrm{H}_{2} \rightarrow \mathrm{C}_{\mathrm{H}_{4}}
$$$$
\mathrm{r}_{\mathrm{CH}_{4} 1}=\mathrm{A}_{\mathrm{CH}_{4} 1} \mathrm{P}_{\mathrm{C}} \mathrm{P}_{\mathrm{H}_{2}} 2\left(1-\frac{1}{\mathrm{~K}_{\mathrm{CH}_{4} 1}} \frac{\mathrm{P}_{\mathrm{CH}_{4}}}{\mathrm{P}_{\mathrm{C}}\left(\mathrm{P}_{\mathrm{H}_{2}}\right)^{2}}\right) \exp \left(\frac{-\mathrm{E}_{\mathrm{CH}_{4} 1}}{\mathrm{~T}}\right) \log _{10} \mathrm{~K}_{\mathrm{CH}_{4} 1}=\frac{\alpha}{\mathrm{T}}+\beta
$$$$
\text { - } \mathrm{CO}+3 \mathrm{H}_{2} \leftrightarrow \mathrm{CH}_{4}+\mathrm{H}_{2} \mathrm{O}
$$$$
\mathrm{r}_{\mathrm{CH}_{4}(2)=\mathrm{A}_{\mathrm{CH} 4}(2)} \mathrm{P}_{\mathrm{CO}} \mathrm{P}_{\mathrm{H}_{2}}{ }^{3}\left(1-\frac{1}{\mathrm{~K}_{\mathrm{CH}_{4}} 2} \frac{\mathrm{P}_{\mathrm{CH}_{4} \mathrm{P}_{\mathrm{H}_{2} \mathrm{O}}} \mathrm{P}_{\mathrm{CO}_{\mathrm{H}} \mathrm{P}_{2} 3}{ }^{3}}{\exp }\left(\frac{-\mathrm{E}_{\mathrm{CH}_{4} 2}}{\mathrm{~T}}\right) \log _{10} \mathrm{~K}_{\mathrm{CH}_{4}} 2=\frac{\alpha}{\mathrm{T}}+\beta\right.
$$

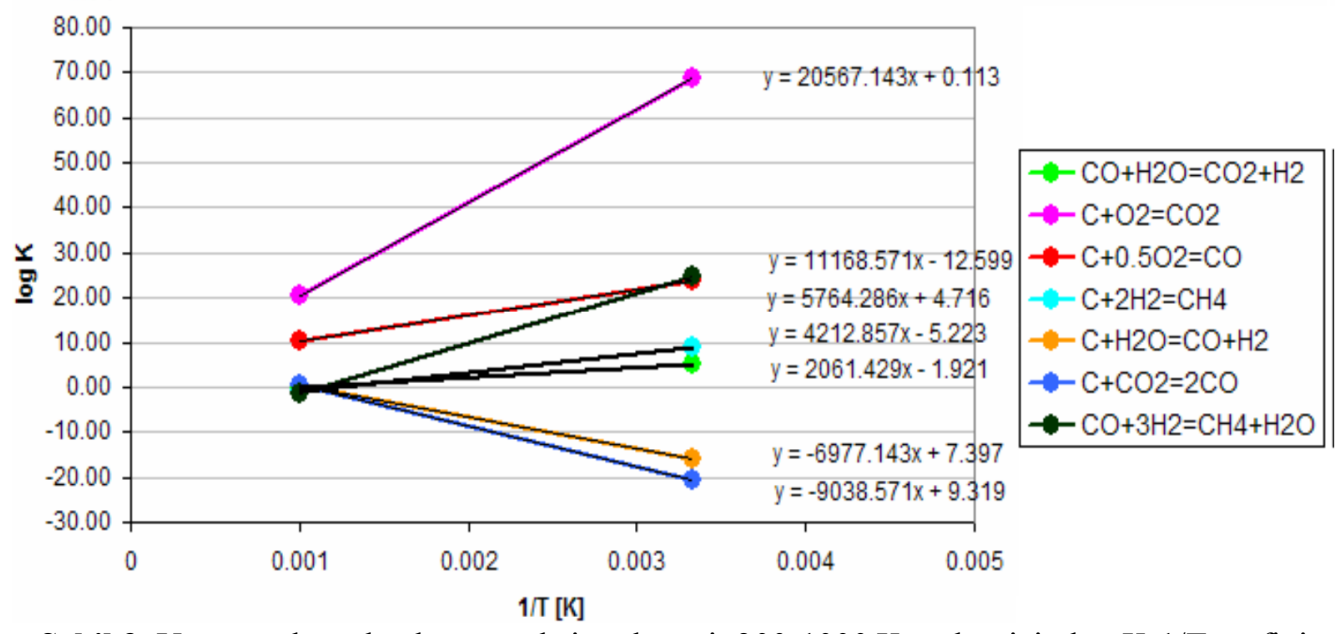

Şekil 3. Yanma odasında oluşan reaksiyonlara ait 300-1000 K aralığı için log K-1/T grafiği (The reaction that occurs in the combustion chamber of 300-1000 K range for $\log \mathrm{K}-1 / \mathrm{T}$ graph) 
3. FARKLI ATIK-KÖMÜR KARIŞIMLARININ ANALITIK YÖNTEM VE NÜMERİK OLARAK MODELLENMESİ (ANALYTICAL METHOD AND A PACK THE PROGRAM MODELLING OF DIFFERENT WASTE-COAL MIXTURE)

$\mathrm{Bu}$ çalışmada evsel katı atıkların gazlaştırılması üzerine bir analitik modelleme yazılımı yapılmış ve bir paket program kullanarak birbiri ile yaklaşımları incelenmiştir. Yapılan çalışmada ilgili gazlaşma reaksiyonları analitik olarak modellenmiştir. Sonuç olarak bu iki model sonuçları aynı türde atıklar ve kömür karışımları için karşılaştırılmıştır.

\subsection{Analitik Modelleme (Analytical Modelling)}

Yapılan literatür taraması sonucunda da görüldüğü gibi kazan içerisinde birçok kimyasal reaksiyon gerçekleşmektedir. Bu çalışmada aşağıda verilen temel beş reaksiyon dikkate alınmıştır.

$\mathrm{C}+\mathrm{H}_{2} \mathrm{O} \leftrightarrow \mathrm{CO}+\mathrm{H}_{2}$ (Endotermik gazlaştırma yükseltgenme reaksiyonu)

$\mathrm{C}+\mathrm{CO}_{2} \leftrightarrow 2 \mathrm{CO}$ (Endotermik Boudouard denkliği)

$\mathrm{C}+2 \mathrm{H}_{2} \leftrightarrow \mathrm{CH}_{4}$ (Ekzotermik metan oluşum denkliği)

$\mathrm{CH}_{4}+\mathrm{H}_{2} \mathrm{O} \leftrightarrow \mathrm{CO}+3 \mathrm{H}_{2}$ (Endotermik metan bozunum denkliği)
$\mathrm{CO}+\mathrm{H}_{2} \mathrm{O} \leftrightarrow \mathrm{CO}_{2}+\mathrm{H}_{2}$ (Ekzotermik gaz-su dönüşüm denkliği)

Yukarıda yazılmış olan reaksiyonları literatürde Mountouris ve arkadaşları aşağıdaki genel denklikle ifade etmişlerdir [22].

$\mathrm{C}_{(\mathrm{x})} \mathrm{H}_{(\mathrm{y})} \mathrm{O}_{(\mathrm{z})}+\mathrm{wH}_{2} \mathrm{O}+\mathrm{mO}_{2}+3,76 \mathrm{mN}_{2} \rightarrow \mathrm{n}_{1} \mathrm{H}_{2}+\mathrm{n}_{2} \mathrm{CO}$

$+\mathrm{n}_{3} \mathrm{CO}_{2}+\mathrm{n}_{4} \mathrm{H}_{2} \mathrm{O}+\mathrm{n}_{5} \mathrm{CH}_{4}+\mathrm{n}_{6} \mathrm{~N}_{2}+\mathrm{n}_{7} \mathrm{C}$

20 numaralı denklik kullanılmış, $\mathrm{n}_{5}$ ve $\mathrm{n}_{7}$ değerlerinin sıfır olduğu kabul edilerek kütlesel içerikleri bilinen şehir çöpü ve kömür karışımlarının gazlaştırma ürün içerikleri analitik olarak hesaplanmıştır. Sonuçlar Tablo 2'de karşılaştırmalı olarak verilmiştir. İthal kömürün kütlesel bazda elementer analizi Tablo 3 de verilmiştir.

\subsection{Paket Program ile Modelleme (Modeling with Package Programs)}

Çalıșmanın bu bölümünde, içeriği bilinen evsel katı atığın ve ithal kömürün gazlaştırılması işlemleri bir paket programı (VMGSim) yardımıyla modellenmiş ve gazlaştırma işlemi sonucunda açığa çıkan sentez gazının her bir modelleme için içerikleri hesaplanmıştır. Ortalama bir şehir çöpünün atık kompozisyonları Tablo 2'de verilmiştir. Yapılan çalışmada, yakıtlar ile atıkların birlikte kullanıldığında açı̆̆a çıkan sentez gazının kütlesel içeriği ve dolayısıyla kalorifik değerinin değişimini incelemek amacıyla evsel katı atık ve ithal kömür ayrı

Tablo 2. Şehir çöpünün kütlesel atık kompozisyonu (Content of municipal solid waste) [23]

\begin{tabular}{|c|c|c|c|}
\hline Bileşen & Yüzde içerik & Bileşen & Yüzde içerik \\
\hline Kağıt & 50,0 & $\mathrm{C}$ & 47,9 \\
\hline Talaş & 3,0 & $\mathrm{H}$ & 6,0 \\
\hline Odun & 11,0 & $\mathrm{~N}$ & 1,2 \\
\hline Sebze atıkları & 3,7 & $\mathrm{Cl}$ & 0,1 \\
\hline Kumaş & 5,5 & $\mathrm{~S}$ & 0,3 \\
\hline Plastik & 10,0 & $\mathrm{O}$ & 32,9 \\
\hline Kauçuk & 3,5 & $\mathrm{SiO}_{2}$ & 11,7 \\
\hline Reçineler & 1,0 & \multirow{5}{*}{\multicolumn{2}{|c|}{$\begin{array}{l}\text { Alt 1sıl Değeri: } 12400 \mathrm{~kJ} / \mathrm{kg} \\
\text { Nem Oranı: } \% 30\end{array}$}} \\
\hline Elektronik atıkları & 3,0 & & \\
\hline İnşaat atıkları & 4,5 & & \\
\hline Cam & 4,0 & & \\
\hline Diğger & 0,8 & & \\
\hline
\end{tabular}

Tablo 3. İthal kömürün kütle içeriği (Mass content of the imported coal) [24]

\begin{tabular}{|l|l|l|c|c|c|c|c|c|c|c|c|}
\hline Bileşen & $\mathrm{C}$ & $\mathrm{O}$ & $\mathrm{H}$ & $\mathrm{N}$ & $\mathrm{S}$ & $\mathrm{SiO}_{2}$ & $\mathrm{Al}_{2} \mathrm{O}_{3}$ & $\mathrm{Fe}_{2} \mathrm{O}_{3}$ & $\mathrm{CaO}$ & $\mathrm{MgO}$ & $\mathrm{Na}_{2} \mathrm{O}$ \\
\hline $\begin{array}{l}\text { \% } \\
\text { Içerik }\end{array}$ & 61,70 & 13,20 & 4,10 & 1,20 & 0,39 & 11,17 & 4,42 & 1,97 & 1,18 & 0,37 & 0,30 \\
\hline
\end{tabular}


ayrı ve Tablo 4'de gösterilen oranlarda karıştırıldığı düşünülerek hem analitik model ile hem de paket program ile çözülerek sonuçlar incelenmiştir. Evsel katı atık ve kömür tek başlarına modellenmesinin yanı sira $\% 25-\% 75, \% 50-\% 50$ ve $\% 75-\% 25$ oranlarında karıştırılarak modellenmiştir. Ayrıca modellemede esas alınan karışımların kütlesel kompozisyonları Tablo 5'de gösterilmiştir. Tablo 6'da modellemeler sonucunda hesaplanan sentez gazı kütlesel içerikleri sunulmuştur.

Tablo 4. Modellemelerde kullanılan atık ve kömür yüzdeleri (Models in the percentages of the waste and coal.)

\begin{tabular}{|c|c|c|}
\hline 1.Modelleme & $\% 100$ Atık & $\%$ Kömür \\
\hline 2.Modelleme & $\% 75$ Atık & $\% 25$ Kömür \\
\hline 3.Modelleme & $\% 50$ Atık & $\% 50$ Kömür \\
\hline 4.Modelleme & $\% 25$ Atık & $\% 75$ Kömür \\
\hline 5.Modelleme & $\% 0 \quad$ Atık & $\% 100$ Kömür \\
\hline
\end{tabular}

Tablo 5. Modellemelerde kullanılan besleme kompozisyonlar1 (Composition of the fuel used in the modeling)

\begin{tabular}{|l|c|c|c|c|c|}
\hline Bileșen & $\begin{array}{l}\mathbf{1 . M o d e l l e m e ~} \\
\text { (\%100 MSW) }\end{array}$ & $\begin{array}{l}\text { 2.Modelleme } \\
\text { (\%75MSW\%25 } \\
\text { Kömür) }\end{array}$ & $\begin{array}{l}\text { 3.Modelleme } \\
\mathbf{( \% 5 0 M S W \% 5 0 ~} \\
\text { Kömür) }\end{array}$ & $\begin{array}{l}\text { 4.Modelleme } \\
\text { (\%25MSW\%75 } \\
\text { Kömür) }\end{array}$ & $\begin{array}{l}\text { 5.Modelleme } \\
\text { (\%100 Kömür) }\end{array}$ \\
\hline $\mathrm{C}$ & 47,90 & 51,35 & 54,80 & 58,25 & 61,70 \\
\hline $\mathrm{O}$ & 32,90 & 27,935 & 23,05 & 18,125 & 13,20 \\
\hline $\mathrm{H}$ & 6,00 & 5,525 & 5,05 & 4,575 & 4,10 \\
\hline $\mathrm{N}$ & 1,20 & 1,20 & 1,20 & 1,20 & 1,20 \\
\hline $\mathrm{S}$ & 0,30 & 0,3225 & 0,345 & 0,3675 & 0,39 \\
\hline $\mathrm{SiO}_{2}$ & 11,60 & 11,4925 & 11,385 & 11,2775 & 11,17 \\
\hline $\mathrm{Al}_{2} \mathrm{O}_{3}$ & - & 1,105 & 2,210 & 3,315 & 4,42 \\
\hline $\mathrm{Fe}_{2} \mathrm{O}_{3}$ & - & 0,4925 & 0,9850 & 1,4775 & 1,97 \\
\hline $\mathrm{CaO}^{\mathrm{MgO}}$ & - & 0,2950 & 0,5900 & 0,8850 & 1,18 \\
\hline $\mathrm{Na} 2 \mathrm{O}$ & - & 0,0925 & 0,185 & 0,2775 & 0,37 \\
\hline $\mathrm{Nem}$ & - & 0,075 & 0,150 & 0,2250 & 0,30 \\
\hline $\begin{array}{l}\mathrm{Is} 1 \mathrm{Değer} \\
(\mathrm{kj} / \mathrm{kg})\end{array}$ & 12400 & 18,75 & 17,00 & 15,50 & 14,00 \\
\hline
\end{tabular}

Tablo 6. Modellemeler sonucunda hesaplanan sentez gazı kompozisyonları (As a result of modelling the calculated synthesis gas compositions)

\begin{tabular}{|c|c|c|c|c|c|c|c|c|c|c|c|c|c|c|c|}
\hline $\begin{array}{l}\text { Sentez Gazı } \\
\text { Bileşenleri }\end{array}$ & $\begin{array}{l}\% 100 \\
\text { MSW } \\
\text { P }\end{array}$ & $\begin{array}{l}\% 100 \\
\text { MSW } \\
\text { AÇ }\end{array}$ & $\begin{array}{l}\% \\
\text { Fark }\end{array}$ & $\begin{array}{l}\% 75 \\
\text { MSW- } \\
\% 25 \\
\text { Kömür } \\
\text { P }\end{array}$ & $\begin{array}{l}\% 75 \\
\text { MSW - } \\
\% 25 \\
\text { Kömür } \\
\text { AÇ }\end{array}$ & $\begin{array}{l}\% \\
\text { Fark }\end{array}$ & $\begin{array}{l}\text { \%50 } \\
\text { MSW- } \\
\text { \%50 } \\
\text { Kömür } \\
\text { P }\end{array}$ & $\begin{array}{l}\text { \%50 } \\
\text { MSW- } \\
\text { \%50 } \\
\text { Kömür } \\
\text { AÇ }\end{array}$ & $\begin{array}{l}\% \\
\text { Fark }\end{array}$ & $\begin{array}{l}\text { \% 25 } \\
\text { MSW-\% } \\
75 \\
\text { Kömür } \\
\text { P }\end{array}$ & $\begin{array}{l}\% 25 \\
\text { MSW- } \\
\% 75 \\
\text { Kömür } \\
\text { AÇ }\end{array}$ & $\begin{array}{l}\% \\
\text { Fark }\end{array}$ & $\begin{array}{l}\% 100 \\
\text { Kömür } \\
\text { P }\end{array}$ & $\begin{array}{l}\text { \% } 100 \\
\text { Kömür } \\
\text { AÇ }\end{array}$ & $\begin{array}{l}\% \\
\text { Fark }\end{array}$ \\
\hline Azot & 14,339 & 16,03 & $-10,5$ & 27,042 & 27,78 & $-2,65$ & 36,028 & 35,56 & 1,3 & 42,87 & 43,47 & $-1,38$ & 48,585 & 49,101 & $-1,12$ \\
\hline Hidrojen & 43,078 & 42,178 & 2,07 & 32,626 & 33,32 & $-2,08$ & 25,834 & 27,95 & $-7,57$ & 20,27 & 21,3 & $-4,84$ & 15,856 & 16,95 & $-6,45$ \\
\hline Hidrojen Siyanat & 0,088 & - & - & 0,075 & - & - & 0,068 & - & - & 0,06 & - & - & 0,055 & - & - \\
\hline Hidrojen Sülfit & 0,086 & - & - & 0,08 & - & - & 0,076 & - & - & 0,073 & - & - & 0,07 & - & - \\
\hline $\mathrm{Su}$ & 1,255 & 1,8 & 30,27 & 2,36 & 0,44 & 81,35 & 1,89 & 1,02 & 46,03 & 2,515 & 0,71 & $\begin{array}{c}+71 \\
77\end{array}$ & 2,577 & 0,95 & 63,13 \\
\hline Karbon Monoksit & 40,29 & 38,88 & 3,5 & 36,72 & 37,67 & $-2,52$ & 35,023 & 35,18 & $-0,44$ & 32,81 & 33,01 & $-0,6$ & 31,224 & 30,68 & 1,74 \\
\hline Karbon Dioksit & 0,635 & 1,1 & 42,27 & 0,89 & 0,77 & 13,48 & 0,906 & 0,27 & 70,2 & 1,24 & 1,52 & 18,42 & 1,479 & 2,31 & 35,97 \\
\hline Amonyak & 0,22 & - & - & 0,19 & - & - & 0,169 & - & - & 0,151 & - & - & 0,137 & - & - \\
\hline Karbonil Sülfit & 0,01 & - & - & 0,009 & - & - & 0,008 & - & - & 0,008 & - & - & 0,008 & - & - \\
\hline
\end{tabular}




\section{SONUÇLAR VE TARTIŞMA (RESULTS AND DISCUSSION)}

Çalışmada; paket program yardımıyla kütlesel içerikleri ve 1 sıl kapasiteleri bilinen evsel katı atık ve ithal kömür karışımları ile beş adet modelleme yapılmıştır. Bu modellemelerin amacı çeşitli karışım miktarları ile oluşturulan beslemelerin gazlaştırılması ile açı̆̆a çıkan sentez gazlarının içeriklerinin incelenmesidir. Sentez gazının içeriğinin beslemenin kütlesel içeriklerine bağlı olduğu gözlenmiştir. Gazlaşma reaksiyonları oluşurken ortamda yeterli nem olması durumunda sentez gazı içerisinde bulunan hidrojen ve karbon monoksit miktarının arttığ gözlenmektedir. $\mathrm{Bu}$ nedenle beslemenin içeriğinde yeteri kadar nemin bulunması tercih edilmelidir. Benzer şekilde gazlaşma reaksiyonları olurken, oluşan sentez gazının içeriğinde bulunan karbon dioksit ve karbon monoksit miktarının artması için ortama beslenecek olan oksijen miktarının artması gerekmektedir.

Tablo 5.'te görüldüğü üzere evsel katı atık, ithal kömür ve bu iki atığın çeşitli oranlarda karıştırılmış hali, hem analitik yöntem ile hem de bilgisayar programı ile modellenmiştir. Burada dikkat çeken husus, \% 100 evsel katı atığın modellenmesi sonucunda hesaplanan hidrojen miktarı \% 100 kömür ve evsel katı atık-kömür karşımına oranla çok daha yüksektir. Bunun temel nedeni, evsel katı atıkların içerisinde bulunan nem miktarının çok daha fazla olmasidir.

Önceki bölümlerde yer alan Kinetik Parametreler başlığı incelenirse, Denklem 3'te de görüleceği üzere ortamda yeterli miktarda nem bulunursa açı̆̆a çıkan CO miktarı da o oranda fazla olacaktır. Tablo 6' da görüldüğü gibi \% 100 şehir çöpü, karışım ve kömüre oranla daha fazla nem içerdiği için gazlaşma ürünlerinde $\mathrm{CO}$ miktarı diğerlerine oranla daha fazla olmuştur. Ayrıca evsel katı atık modellemesi neticesinde hesaplanan azot miktarı \% 100 kömür ve evsel katı atık-kömür karşımına oranla çok daha azdır. Bunun nedeni, evsel katı atık, gazlaşma sırasında CO ve $\mathrm{CO}_{2}$ oluşabilmesi için gerekli $\mathrm{O}_{2}$ 'i bünyesinde daha fazla bulundurmakta (kütlesel olarak \% 32,9) ve bu nedenle daha az oksitleyici havaya ihtiyaç duymaktadır. Kömür ve kömür-atık karşımı ise içeriğinde bulunan $\mathrm{O}_{2}$ 'nin azlığından (kütlesel olarak sırasıyla \%13,2 ve \%23,05), gazlaşma neticesinde CO ve $\mathrm{CO}_{2}$ oluşabilmesi için daha fazla oksitleyici havaya ihtiyaç duymaktadır. $\mathrm{Bu}$ sebebten dolayı hava/atık karışımları, evsel katı atık için 0,416 mol hava/mol atık, kömür için 1,207 mol hava/mol kömür, atıkkömür karşımı için ise 2,023 mol hava/mol karışım olarak alınmıştır. Burada, en fazla oksitleyici hava kömürün gazlaştırılmasında kullanıldığı için, havanın içerisindeki azot miktarından dolayı gazlaşma ürünü sentez gazının içerisinde en fazla azotu kömürün gazlaşma ürünü ihtiva edecektir. Atık bertaraf tesislerinde her ne kadar açığa çıkan 1sı ve dolayısıyla elektrik enerjisi önemli olsa da bu tesislerin ana amacı tehlikeli atıkların yasa ve yönetmeliklere uygun bir şekilde bertaraf edilmesidir. Konuya bu şekilde bakıldığında plazma teknolojisi diğer yakma teknolojilerine göre çok daha az risk taşıyan ve güvenilir bir teknolojidir. Gazlaştırma sırasında çok yüksek sıcaklıklara çıkılmasından dolayı yakma tesisleri için en büyük sorun olan dioksinler ve furanlar oluşmamaktadır. Ayrıca bacadan atılan ağır metaller, gazlaştırma sırasında kazanın dibinde camlaşmış çamur olarak birikmekte, zararsız bir şekilde dışarı alınmakta ve dolgu malzemesi olarak yeniden kullanılabilmektedir. $\mathrm{Bu}$ nedenle plazma teknolojisi ile bertaraf, diğer yakma teknolojilerine göre daha az atık açığa çıkarıp daha çevreci bir rol üstlenmektedir.

Yapılan çalışmanın sonucunda; çok yeni bir teknoloji olan plazma gazlaştırma teknolojisi ile gazlaştırmanın analitik ve bilgisayar modellemeleri yapılmış olup elde edilen ürünlerin miktarları karşılaştırılıp ülkemizde bu teknolojiyi kullanacak sanayicimize matematiksel veriler verilip, yol gösterilmesi amaçlanmıştır.

\section{SEMBOLLER VE KISALTMALAR (SYMBOLS AND NOMENCLATURE)}

$\begin{array}{ll}\mathbf{A} & \text { Frekans faktörü } \\ \mathbf{E}_{\text {Elekterik }} & \text { Elektrik enerjisi, watt } \\ \mathbf{E} & \text { Aktivasyon enerjisi } \\ \mathbf{H}^{\mathbf{o}}{ }_{\mathbf{f}} & \text { Beslemenin standart entalpisi } \\ \mathbf{H}^{\mathbf{0}}{ }_{\text {ref }} & \text { Referans oluşum entalpisi } \\ \mathbf{H}^{\mathbf{0}}{ }_{\mathbf{T}} & \text { T sıcaklığındaki oluşum entalpisi } \\ \mathbf{K} & \text { Reaksiyon denge katsayısı } \\ \mathbf{k} & \text { Reaksiyon hız sabiti } \\ \mathbf{m} & \text { Plazma akışkanı(hava) kütle akışı } \\ \mathbf{P} & \text { Basınç, Pascal } \\ \mathbf{r} & \text { Reaksiyon hizı } \\ \mathbf{R} & \text { Gaz sabiti, kj/kgK } \\ \mathbf{T} & \text { Sicaklık, }{ }^{\circ} \mathrm{C},{ }^{\circ} \mathrm{K} \\ \mathbf{V} & \text { Hacim, m }{ }^{3} \\ \mathbf{w} & \text { Nem miktarı (\%) } \\ \mathbf{X}_{\mathbf{i}} & \text { i bileşeninin molar kesri, (/) } \\ \mathbf{Q} & \text { Isı enerjisi, kj/kmol }\end{array}$

\section{YUNAN HARFLERI (GREEK CHARACTERS)}

$\begin{array}{ll}\boldsymbol{\alpha} & \text { Reaksiyon hız ifadesi katsayısı } \\ \boldsymbol{\beta} & \text { Reaksiyon hız ifadesi katsayısı } \\ \boldsymbol{\varepsilon} & \text { Kimyasal ekserji }\end{array}$

\section{KAYNAKLAR (REFERENCES)}

1. Anonim: Ankara Sanayi Odası "Atık Nedir?"

2. http://www.aso.org.tr/kurumsal/index.php?sayfa no $=55,2011$.

3. TUBİTAK MISAG 195 Nolu proje, "Türkiyede Biyokütleden Temiz Enerji Elde Edilmesinin Araştırılması" 2001. 
4. British Council Partnership Project, "Comparative Study of Energy Recovery from Turkish Biomass”, Gazi Üniverstesi, ODTÜ, University of Sheffield, 2001.

5. DPT 2002K120250-14 Kod nolu proje "Tarımsal ve endüstriyel atıkların yok edilmesi ve enerji geri kazanımı ile ilgili yanma ve emisyon araştırmaları", 2001.

6. Gomeza, E., Amutha Rania, D., "Thermal plasma technology for the treatment of wastes: A critical review" Journal of Hazardous Materials, Cilt 161, No 2, 614-626, 2009.

7. R. W. BECK INC "City of Honolulu Review of Plasma Arc Gasification and Vitrification Technology for waste disposal", Final Report, Municipality of Honululu, 2003.

8. Dereli C., Topal H., "Energy production from municipal solid waste using plasma gasification", Proceedings of the Sixth International Exergy, Energy and Environment Symposium (IEEES6), Recep Tayyip Erdoğan University, Rize, 291298, 1-4 Temmuz 2013.

9. Messerle V.E., Ustimenko A.B., "Plasma-Fuel Systems Utilization For Ecological And Energy Efficiency of Thermal Power Plants", Proceedings of the Sixth International Exergy, Energy and Environment Symposium (IEEES6), Recep Tayyip Erdoğan University, Rize, 763775, 1-4 Temmuz 2013.

10. Messerle V.E., Ustimenko A.B., "Plasma Technologies of Solid and Saseous Fuels Processing", Proceedings of the Sixth International Exergy, Energy and Environment Symposium (IEEES-6), Recep Tayyip Erdoğan University, Rize, 776-788, 1-4 July 2013.

11. David H.F. Liu, Bela G. Liptak, Environmental Engineers' Handbook, Second Edition, Lewis Publishers, 1997.

12. Vaidyanathan, A., Mulholland, J., "Characterization of fuel gas products from the treatment of solid waste streams with a plasma arc torch" Journal of Environmental Management, Cilt 82, No 1, 77-82, 2007.

13. Tzeng, C., Kuo, Y., "Treatment of radioaktive wastes by plasma incineration and vitrification for final disposal" Journal of Hazardous Materials, Cilt 58, No 1-3, 207-220, 1998.

14. Moustakas, K., Fatta, D., "Demonstration plasma gasification/vitrification system for effective hazardous waste treatment" Journal of Hazardous Materials, B123, 120-126, 2005.

15. Galeno, G., Minutillo, M., "From waste to electricity through integrated plasma gasification/fuel cell (IPGFC) system" Intrnational Journal of Hydrogen Eneregy, Cilt 36, No 2, 1692-1701, 2011.

16. Huang, H., Tang, L., "Treatment of organic waste using thermal plasma pyrolysis technology" Energy Conversion and Management, Cilt 48, No 4, 1331-1337, 2007.

17. Kataou, K., Asou, T., "Melting municipal solid waste incineration residue by plasma melting furnace with a graphite electrode" Thin Solid Films, 386, 183-188, 2000.

18. Mountouris, A, Voutsas, E, "Solid waste plasma gasification: Equilibrium model development and exergy analysis", Energy Conversion and Management, 47, 1723-1737, 2006.

19. Topal, H., Toraman, Y., Katı Atık ve Arıtma Çamurlarının Değerlendirmesinde Alternatif Termal Teknolojiler ve Uygulamaları, Journal of The Faculty of Engineering and Architecture of Gazi University, Cilt 18, No 1, 19-33, 2003.

20. Oost, V., Hrabovsky, M., "Pyrolysis of waste using a hybrid argon-water stabilized torch", Vacuum, Cilt 80, No 11-12, 1132-1137, 2006.

21. The Northspan Group Inc., Does it make sense to move forward with a full feasibility analysis?, Aitkin County Plasma Gasification Study, Duluth, 3, 2008.

22. Virtual Material Group Inc., VMGSIM ver 6.0 Program Tutorial, 1715-1736, 2010.

23. Mountouris, A., Voutsas, E., "Plasma gasification of sewage sludge: Process development and energy optimization", Energy Conversion and Management, Cilt 49, No 8, 2264-2271, 2008.

24. İnternet: T.C. Çevreve Orman Bakanlı̆̆ Bilgiler" http://www.cevreorman.gov.tr, 2008.

25. Akçura, F. ve Gerger M., Başlıca Türk Kömürlerinin özellikleri MTA Enstitüsü, Ankara, 1982. 
